\title{
New Critical Thinking: What \\ Wittgenstein Offered \\ by Sean Wilson
}

\section{Camilla Kronqvist}

Wilson, Sean, New Critical Thinking: What Wittgenstein Offered. Lanham: Lexington Books, 2018. ISBN: 978-1-4985-8359-6. 171 pp.

One of the things Sean Wilson seems to have learnt from Wittgenstein is the significance of a good foreword. Thus, he begins his introduction with stating "Ludwig Wittgenstein changed my intellectual life" (xxi). The statement itself is in some ways not very startling. For someone who was very keen not to attract followers, and in many cases advised his students to seek out other careers than philosophy, Wittgenstein clearly had a fascinating effect on many. The stories abound with students taken up his gestures and manners, thus bearing mark of his influence on them. Even among students of him, such as myself, who never had the chance of meeting him personally, but have approached him through his works and works by his students, there often appears to be a need to take a stand not only on the philosophy but on the man. This is so, even if these stands amount to the mere realization that he may not have been that pleasant as a person, or that one would not have taken a liking to him personally.
Yet, since Wittgenstein has attracted this kind of attention, it may be instructive to begin a dissemination of Sean Wilson's work in New Critical Thinking: What Wittgenstein Offered by considering this claim. This allows us to see what difference Wilson thinks this makes to the understanding of Wittgenstein's philosophy that he offers, and to discern what can be thought of as new in the form of thinking Wilson presents as Wittgenstein's.

Staying true to a manner of thinking, which to me is very Wittgensteinian, it is only proper to begin by ascertaining that the sentence "Wittgenstein changed my intellectual life", can mean different things depending on the specific context in which it is made. Not only can the sentence be used in different ways, as a description of one's intellectual background, as a confession, as an expression, the word Wittgenstein itself can stand in for different things, such as "the work of Wittgenstein", "the experience of reading Wittgenstein" 
or, "studying the philosophy of Wittgenstein for professor $\mathrm{x}$ ". What we are to make of this claim in a concrete case will also depend on whether I use those words to portray an episode of my life, give expression to a philosophical perspective or comment on some aspect of Wittgenstein's particular style of writing. I myself could have used the words to express my indebtedness to the philosophical environment I grew into during my studies, as well as the crucial role it had for how I have come to understand philosophical problems. It is even highly probable that I have used some combination of these words to convey this realisation in conversation.

Wilson seems to be saying something similar, yet, he also wants to make a stronger claim. He does not simply equate the philosopher with his work, he wants to say that there was something in the person of this philosopher, in "Ludwig Wittgenstein", which occasioned him to regard the task of philosophy in a distinct way. There was, as it were, something in Wittgenstein's psyche that allowed him to grasp the cognitive causes of philosophical problems, and to device ways of dissolving these spells and deformations of the intellect, which were not available to others.

The more specific claim that Wilson makes is that Wittgenstein was hypersensitive to what Wilson describes as three "natural phenomena" of the intellect, which "underlie the social behavior of making assertions" (xiv). The first of these is "the social traits implicated in word use" (xxi).
Here Wilson thinks of the different features of word use we may point to in describing the meaning of a word. When saying things like "Monopoly is a game", e.g. we describe a "game" as an activity, played for fun, adhering to certain rules, etc. (45-46). When we by contrast say, "Love is a game", we draw on different features of games, such as their reciprocity, to present a specific perspective of love (47). The second is "(b) the task-functions signified in communication" (xxi), by which Wilson means the different deeds done by uttering words. In particular, he emphasizes the intellectual tasks we perform in language, such as memorizing labels, telling news, stating affiliation, translating expressions or irritating persons. (Wilson, however, prefers to put this in a slightly more technical form such as "MEMORIZE(label)" or "IRRITATE(person)", 61, 63). The final "component" of Wittgenstein's philosophy is "the pictures that flash before the mind's eye." (xxi), the mental images that may or may not accompany speech and listening but, importantly, are not reducible to understanding. Comprehending task functions are thus centrally not to be seen as the same as having a mental image. Equipped with these Wilson then goes on to consider how this way of thinking may affect our understanding of questions of meaning, aspects, ethics and religion, addressing e.g. the role of connoisseurship in moral judgement.

Wilson's introduction of social traits and task functions as a means of breaking up the uses of language, the 
ones we can in some cases identify as meaning, is both innovative and interesting. It is quite thinkable that someone who were not acquainted with Wittgenstein's philosophy, or even reluctant to engage with it on beforehand, could come to see its relevance through Wilson's discussion. It is also easy to be smitten by both his ambition and enthusiasm, and at least feel amused by his original use of pictures to convey the point that Wittgenstein was extraordinarily attentive to mental images holding us captive. Rather than spending undue time on exegesis, the book presents an author keen on engaging his readers in new and original work, on making them think, an attempt that throughout is commendable. The speed with which Wilson takes on topics, such as ethics and religion, which have occupied Wittgensteinian philosophy to an extent that would go unnoticed to anyone new to Wittgenstein reading this book, however, is sometimes somewhat daunting. Although there is often mention of what a Wittgensteinian would say or do, I many times wished for more mention of who they are, and what they would have to say on related issues.

My main concern, however, is Wilson's reliance on features of Wittgenstein's biography for presenting this new form of critical thinking. When Wilson emphasizes that he needs part one (xi), which gives his reading of Wittgenstein as a person and his distinct intellect, I, after reading the book, want to exclaim as emphatically, "no, you don't". I do so, partly because I disagree with
Wilson's suggestion that the uniqueness of Wittgenstein's philosophy can be boiled down to these three aspects of his intellect. These disagreements turn around more specific objections, such that Wilson treats Wittgenstein's discussion of pictures in a much too literal sense, and more general concerns about the attempt to compress Wittgenstein's thought into a formula. Does this not too easily invite one to elaborate on a system, say, taking upon oneself to list all the taskfunctions in language? It is also unclear to me why Wittgenstein, if this was indeed the core of what he wanted to say, did not succeed in saying it clearly. It does not seem to take a genius to see these things, and although I am uncertain whether I want to give Wittgenstein that title, he is certainly a much more interesting and complex thinker than what emerges through these three features.

What worries me most, however, is Wilson's bringing Wittgenstein's philosophical writings back on his psychology. Wilson is certainly not the first to make such claims. Jaakko Hintikka (2000) made a case for Wittgenstein being a dyslexic, and there has also been speculations as to whether Wittgenstein had Aspergers (see e.g. Fitzgerald 2004). Now, Wilson makes clear, that his desire is not to diagnose Wittgenstein, but merely to provide an explanation of his exceptional psychology (27). This, however, still raises the question why he does not settle with description, the alternative often offered by Wittgenstein to counter the scientific desire for explanation, to present what 
he finds unique in Wittgenstein's writing.

Such an approach could have allowed Wilson to pose important questions about the presence of the philosopher in his work. It could have involved him in a discussion of the implications and character of Wittgenstein's diverse therapies and keen attention to questions of methods in attempting to find a suitable form for teaching his philosophy. Using his own terminology Wilson e.g. could have asked what task-functions Wittgenstein's writings could be said to fulfil. Staying more closely to Wittgenstein's concerns, he could have interrogated into the spirit in which Wittgenstein wrote, and the kind of perspective on language use emerging through his work. This could have provided another link to questions of ethics and religion in Wittgenstein's work.

By relying on a psychologising discourse in speaking of the intellect, cognition, and hypersensitivity, however, Wilson's discussion lands him in a view that makes philosophical thinking too mentalistic. When Wilson e.g. suggests that the points he discusses show themselves to anyone who through a reading of Wittgenstein comes to develop the same kind of abnormal sensitivities (xxii), it becomes difficult to distinguish the kind of clarity that a perspicuous presentation of language use and of our possibly distorting tendencies to think about this use can contribute to our philosophical thinking, from a self-confirming bias, which finds proof of one's preestablished theoretical commitment in every instance. If "the thesis" which "shows itself" (xxii), is only that which $\mathrm{I}$, in the light of my theory can be expected to find, there is no way of suggesting that my philosophizing makes me see things in a better light than previously.

"Try to be loved \& not-admired" (CV, 44e), Wittgenstein wrote in an encrypted remark in a notebook, in the midst of reflections on proofs in mathematics and the relation between mathematics and logic. The remark follows on similarly encrypted remarks on the need for courage to overcome or even conquer hopelessness, and for using one's talent in such ways as to produce genius. (The remarks, devoid of context, are collected in Culture and Value, 43e44e). It is far from obvious how one should read these remarks in relation to one another, especially the tension between seeing conquering funk as worthy of admiration, and suggesting that one should not strive to be admired. This is also not the appropriate place to explore these possible connections and disconnections. It is, however, evident that to Wittgenstein the recognition that he was someone who attracted admirers, even among those who also loved him, (cf. CV, 10e on putting a lock on a room, which only those who can open it will understand, not to attract the attention of those who do not understand), appeared as a threat to the kind of clarity, or lucidity, he desired in philosophy as well as in a well lived life. This is so both on the part of him as someone being admired, and on the part of those who admired him. Thus, 
although the felt (psychological) experiences of admiration and love may well coincide, especially in the case of falling in love, it is of ethical significance to mark a conceptual (logical) distinction between admiration and love, as well as to consider what one seeks in admiring and being admired by contrast to loving and being loved.

One aspect of what one may think is failing in the admiration, and the desire for admiration, of which Wittgenstein was critical, the admiration of his genius and of him as a person, is the sense in which he, as someone admired, comes to take up too much of the visual field of the admirer. The admirer, as it were, comes to see the admired one in everything, whereas the task of loving, and the kind of understanding that is expressive of love, also involves coming to acknowledge one's own place in the relationship, and the extent to which what one comes to see in the loved and the admired one, is really an aspect of him, and not a mere mirror of the star struck lover.

Now, in his conviction that he needs Wittgenstein to make his points, Wilson sometimes resembles such an admirer, and sometimes even a star struck lover, who in the end comes to see a mirror of his own understanding in the object of his admiration. Thus, the critical thinking he offers, although innovative and potentially productive in some ways, appears too uncritical in other ways. To counter that impression, I would advise Wilson to invert the quote by Wittgenstein, and "Try to love someone \& not-admire them." (Con- sidering that love as both Wilson and Wittgenstein appears to consider it is a reciprocal relationship, cf. 47). This is not to say that Wilson would need to retract from his initial statement, and downplay the extent to which Wittgenstein changed his intellectual life. It is, however, to suggest that rather than speculating about what it was in Wittgenstein that drove this change in Wilson, and Wittgenstein's whole philosophy, Wilson might have done better to describe what it was in himself, or in his own thinking, that changed through the acquaintance with Wittgenstein's philosophy. This could also be taken as an injunction to speak on his own, and as an acknowledgement that the value of his contribution to philosophy in the end does not hang on Wittgenstein's acumen, but on the kind of clarity and understanding of philosophical problems that Wilson himself succeeds in offering in his writing.

Åbo Akademi University, Finland Camilla.Kronqvist@abo.fi

\section{References}

Fitzgerald, M., 2004. Autism and Creativity: Is There a Link Between Autism in Men and Exceptional Ability? New York: BrunnerRoutledge.

Hintikka, J., 2000. “Wittgenstein's Demon and His Theory of Mathematics". In: T. Demeter, ed., Essays on Wittgenstein and Austrian Philosophy. Amsterdam, New York: Rodopi, 89-108.

Wilson, S., 2018. New Critical Thinking: What Wittgenstein Offered. Lanham: Lexington Books.

Wittgenstein, L., 1998. Culture and Value, rev. ed. Malden: Blackwell Publishing. (CV) 